\title{
Development and evaluation of electrochemical glucose enzyme biosensors based on carbon film electrodes
}

\author{
Monica Florescu ${ }^{\mathrm{a}, \mathrm{b}}$, Christopher M. A. Brett ${ }^{\mathrm{a}, *}$ \\ a Departamento de Química, Universidade de Coimbra, 3004-535 Coimbra, Portugal \\ ${ }^{\mathrm{b}}$ Department of Physics, Transilvania University of Brasov, 2200 Brasov, Romania
}

Received 27 November 2003; received in revised form 1 April 2004; accepted 2 July 2004

Available online 9 August 2004

\begin{abstract}
Electrochemical glucose enzyme biosensors have been prepared on carbon film electrodes made from carbon film electrical resistors. Evaluation and characterisation of these electrodes in phosphate buffer saline solution has been carried out with and without pretreatment by cycling in perchloric acid or at fixed applied potential. Both pretreatments led to a reduction in the carbon surface oxidation peak and enabled better detection of hydrogen peroxide in the $\mathrm{pH}$ range of 5-7. Glucose oxidase enzyme was immobilised on the carbon surface by mixing with glutaraldehyde, bovine serum albumin and with and without Nafion. The performance of these two types of electrode was similar, that containing Nafion being more physically robust. Linear ranges were up to around $1.5 \mathrm{mM}$, with detection limits $60 \mu \mathrm{M}$, and pretreatment of the carbon film electrode at a fixed potential of $+0.9 \mathrm{~V}$ versus SCE for $5 \mathrm{~min}$ was found to be the most beneficial. Michaelis-Menten constants between $5 \mathrm{mM}$ and $10 \mathrm{mM}$ were found under the different experimental conditions. Coating the immobilised enzyme layer with a thin layer of Nafion was found to give similar results in the determination of glucose to mixing it but with benefits against interferences for the analysis of complex matrices, such as wine. Potentialities, for a short-term-use or disposable sensors, are indicated.
\end{abstract}

(C) 2004 Elsevier B.V. All rights reserved.

Keywords: Carbon film; Electrochemical biosensor; Enzyme; Glucose

\section{Introduction}

Biosensors are versatile analytical tools for many applications, since the biorecognition element is chosen so as to be able to interact selectively and specifically with its substrate, while the transducer transforms the resulting information into a measurable signal $[1,2]$. The design and development of biosensors has to consider three aspects: an optimal biorecognition element, a sufficiently sensitive transducer and a good immobilisation method for the biorecognition element on an appropriate material whilst retaining its activity and with sufficient lifetime.

In electrochemical biosensors, enzymes belonging to the family of oxidases are often used. A product of the reaction of the substrate with oxygen catalysed by these enzymes is

\footnotetext{
* Corresponding author. Tel.: +351 239 835295; fax: +351 239835295 . E-mail address: brett@ci.uc.pt (C.M.A. Brett).
}

$\mathrm{H}_{2} \mathrm{O}_{2}$, and its electroactivity can be used to obtain a measurable current signal. For glucose detection, the most widely used biosensors that have been studied are amperometric enzyme-based electrodes $[3,4]$ with carbon or with noble metal electrode substrates such as Au and Pt [5,6].

Carbon is a commonly used solid electrode material [7], particularly glassy carbon due to its wide positive potential window, hardness, low porosity, mechanical stability, and applicability to a wide range of redox systems. Other forms of carbon, such as carbon films, have also been used. These can be obtained by thick-film screen printing technology, which leads to mechanically robust and disposable sensors (see [8] and references therein).

Coating a suitable substrate with a very thin deposit of pyrolytic carbon can offer an interesting alternative [9-11]. It has the anisotropic non-porous properties of glassy carbon, is reproducible, does not require polishing prior to use and can be used as a short-term-use or disposable sensor. 
In particular, carbon film electrical resistors have been made into electrodes, found to have a large potential window after surface pretreatment [12], and have been applied successfully to the determination of trace metal ions, such as copper, zinc and manganese, in complex matrices, without the necessity of the traditional mercury film [13].

Carbon has been the substrate of choice for many enzyme immobilisation studies given the good compatibility between the enzyme layer and the electrode substrate [14]. Evaluation of new enzyme electrode assemblies and configurations has usually been carried out with the glucose oxidase enzyme, as will be done in this work. The most often-used immobilisation methods are: physical adsorption (static adsorption, electrodeposition) [15,16], covalent binding [17], carrier binding (binding of enzymes to water-insoluble carriers), cross-linking (intermolecular cross-linking of enzyme by bifunctional or multifunctional reagents), encapsulation (within a semi-permeable polymer membrane) and entrapment in a polymer matrix or membrane [18-20]. Often electron-transfer mediators, such as Prussian Blue, are incorporated within the enzyme layer or beneath it, to improve the response characteristics [21-23].

The present study deals with the development, evaluation and characterisation of a glucose oxidase (GOx) electrochemical enzyme biosensor on a carbon film electrode support made from a low-cost electrical resistor, which can be employed as a short-term-use or as a disposable sensor. Immobilisation has been carried out by cross-linking without mediator. This work is part of an extensive study concerning characterisation and evaluation of these resistors as supports for electrochemical enzyme biosensors in different situations without and with incorporated mediators. The biosensors are characterised and potentialities for application to the analysis of glucose in wine are indicated.

\section{Experimental}

\subsection{Chemicals}

Glucose oxidase (GOx, EC 1.1.3.4, from Aspergillus niger, 35,600 units/mg, $\alpha-\mathrm{D}(+)$-glucose, glutaraldehyde (GA) $25 \%(\mathrm{v} / \mathrm{v})$ and bovine serum albumin (BSA) were from Sigma, USA. Potassium hexacyanoferrate (II) $\left(\mathrm{K}_{4} \mathrm{Fe}(\mathrm{CN})_{6}\right)$ was obtained from Merck, Germany; Nafion 5\% (v/v) was from Sigma-Aldrich, UK.

For electrochemical experiments, the supporting electrolyte was phosphate buffer saline (PBS) (0.1 M phosphate buffer $+0.05 \mathrm{M} \mathrm{NaCl}, \mathrm{pH} 7$ ). Hydrogen peroxide solutions were calibrated by titration with standardised acidified $\mathrm{KMnO}_{4}$ solution. Glucose standard solutions were prepared by dilution of a $100 \mathrm{mM} \alpha-\mathrm{D}(+)$-glucose stock solution in water. The stock solution was prepared $24 \mathrm{~h}$ before use to establish the anomeric equilibrium between $\alpha$ and $\beta$ forms of D-glucose; it was kept in refrigerator and used within a week. Milllipore Milli-Q nanopure water (resistiv- ity $\geq 18 \mathrm{M} \Omega \mathrm{cm}^{-1}$ ) was used throughout for the preparation and dilution of solutions.

\subsection{Electrochemical measurements}

Measurements were made in a one-compartment cell containing a platinum auxiliary electrode and a saturated calomel electrode (SCE) as reference. Voltammetric and amperometric experiments were carried out using CV-50W Voltammetric analyzer from Bioanalytical Systems, West Lafayette, Indiana, USA, controlled by BAS CV 2.1 software.

\subsection{Preparation of carbon film electrode}

Electrodes were made from carbon film electrical resistors ( $2 \Omega$ nominal resistance) [11]. These resistors are fabricated from ceramic cylinders of length $0.40 \mathrm{~cm}$ and external diameter $0.15 \mathrm{~cm}$ by pyrolytic deposition of carbon at $1100^{\circ} \mathrm{C}$ in an oven containing nitrogen with a small amount of methane; each end of the cylinder is then covered with tight-fitting metal caps, joined to thin conducting wires, for external connection. To make the electrodes one of the metal caps, was removed from one end of the resistor. The conducting wire was sheathed in plastic and the remaining cap was carefully covered with epoxy resin. Following this procedure, the exposed electrode geometric area was $0.20 \mathrm{~cm}^{2}$.

\subsection{Electrode pretreatment}

Carbon film resistor-based electrodes without pretreatment and after electrochemical pretreatment in two different ways were compared in order to develop them as enzyme biosensor for glucose detection. In the first type of pretreatment the electrodes were cycled three times in $1.0 \mathrm{M}$ perchloric acid solution between -0.7 and $+1.0 \mathrm{~V}$ versus SCE, at a scan rate of $50 \mathrm{mV} \mathrm{s}^{-1}$. In the second, a fixed potential of $+0.9 \mathrm{~V}$ versus SCE was applied for $5 \mathrm{~min}$ in PBS solution. After both these procedures the electrodes were washed with Milli-Q water.

\subsection{Enzyme immobilisation}

GOx was immobilised onto the electrode surface by the cross-linking method. A mixture of glutaraldehyde (GA), enzyme and BSA was used.

To prepare $30 \mu \mathrm{l}$ of this mixture, $10 \mu \mathrm{l}$ of GA $(2.5 \% \mathrm{v} / \mathrm{v}$ diluted in water) was added to $25 \mu$ l of enzyme solution. The enzyme solution was prepared by dissolving $40 \mathrm{mg}$ of BSA and $10 \mathrm{mg}$ of GOx in $1 \mathrm{ml}$ of $0.1 \mathrm{M}$ PBS, $\mathrm{pH}$. From this mixture, $10 \mu \mathrm{l}$ was placed onto the surface of working electrode and allowed to dry for at least $1 \mathrm{~h}$ at room temperature.

In order to ensure a good physical stability of the enzyme layer on the electrode surface and also to act as a barrier against interferents, a solution of Nafion was utilized in two different ways. In the first, a volume of $7.5 \mu$ l of Nafion (5\% 
$\mathrm{v} / \mathrm{v}$, in alcohol) was mixed with the solution mixture described above, $10 \mu \mathrm{l}$ of resulting solution was applied to the electrode and allowed to dry for $1 \mathrm{~h}$. In the second, $7.5 \mu \mathrm{l}$ of Nafion solution $(1 \% \mathrm{v} / \mathrm{v}$ and $5 \% \mathrm{v} / \mathrm{v}$ in alcohol) was deposited on the electrode-biosensor assembly after coating with enzyme solution and the assembly left to dry for at least $1 \mathrm{~h}$ at room temperature.

\section{6. $\mathrm{H}_{2} \mathrm{O}_{2}$ and glucose measurements}

$\mathrm{H}_{2} \mathrm{O}_{2}$ and glucose were measured with a carbon film electrode, with and without electrochemical pretreatment, in $10 \mathrm{ml}$ of $0.1 \mathrm{M}$ PBS. The potential was applied to the electrode and the baseline was allowed to stabilise. Aliquots of $\mathrm{H}_{2} \mathrm{O}_{2}$ and glucose stock solution in water were added to the cell such that each addition resulted in a $0.2 \mathrm{mM}$ increment in concentration; the corresponding increase in current was recorded, from which the baseline was subtracted.

\subsection{Analysis of wine samples}

For analysis of wine samples, $25-\mu 1$ aliquots were added to $10 \mathrm{ml}$ of $0.1 \mathrm{M}$ PBS, and the standard addition method was used to determine the glucose concentrations.

Independent analysis of glucose concentrations was done using the standard spectrophotometric enzyme assay kit [24] (Cat 0139106, Boehringer, Mannheim).

\section{Results and discussion}

\subsection{Electrode pretreatment procedure}

In order to obtain reliable and reproducible GOx-based biosensors, two types of pretreatment were investigated. In the first of these, some of the carbon film electrodes were subjected to an electrochemical pretreatment procedure by cycling in perchloric acid between $-0.7 \mathrm{~V}$ and $+1.0 \mathrm{~V}$ at $50 \mathrm{mV} \mathrm{s}^{-1}$ scan rate, as in [12]. Care was taken not to expose the electrode to extreme potentials corresponding to high anodic or cathodic currents. Under these conditions, the initial oxidation and reduction peaks decreased and a relatively stable response was obtained after three cycles. The effect of the pretreatment was evaluated by comparison with that obtained with the untreated electrode in PBS solution in the potential range to be used for the enzyme biosensor. The influence of $\mathrm{pH}$ on the carbon surface oxidation peak is demonstrated in the cyclic voltammograms of Fig. 1a, becoming less positive as the $\mathrm{pH}$ is increased and the effect of acid pretreatment in removing the oxidation peak is shown in Fig. $1 \mathrm{~b}$ (dotted lines). The voltammograms obtained in PBS clearly indicate the presence of some active groups on the untreated carbon film electrode surface.

Cyclic voltammetry in $2 \mathrm{mM}$ potassium hexacyanoferrate (II) containing solution was also carried out. At carbon electrodes the electrode kinetics of the oxidation reaction is strongly dependent on the state of and species on the electrode surface [12]. There are also ageing effects, which can influence the measured currents, often due to surface blocking, and also the electrode kinetics owing to alterations of the surface groups on the carbon. For the acid pretreated electrode the redox process of $\mathrm{K}_{4} \mathrm{Fe}(\mathrm{CN})_{6}$ was more reversible and the anodic to cathodic peak separation was lowered from $154 \mathrm{mV}$ to $110 \mathrm{mV}$ (Fig. 2).

In a second type of pretreatment, untreated electrodes were held at $+0.9 \mathrm{~V}$ for different periods of time and the effect of this surface oxidation was evaluated by $\mathrm{H}_{2} \mathrm{O}_{2}$ detection (see below). The reproducibility was better in this situation, and the background currents also decreased. Consequently, a conditioning time of $5 \mathrm{~min}$ at $+0.9 \mathrm{~V}$ versus SCE was chosen as the best compromise to achieve a consistent improvement of carbon film electrode electrochemical performance in the shortest time. The effect of this pretreatment is also shown in Fig. 1c (dotted lines).

Electrochemical treatment in perchloric acid or holding at fixed positive potential act in different ways on hydrocarbon groups that are on the electrode surface. Acid treatment can determine alterations or removal of some surface groups and polarising at positive potential leads to oxidation of those chemical groups. These processes influence the characteristics and electrochemical behaviour of the sensor as well as its interaction with analytes and adsorbed species or layers.

\subsection{Hydrogen peroxide detection}

Since it was deduced that both the applied potential and $\mathrm{pH}$ value are important in developing a successful detection scheme, the influence of these in hydrogen peroxide oxidation, which is detected in the sensors to be developed, was investigated.

Cyclic voltammograms were recorded between $0.0 \mathrm{~V}$ and $1.0 \mathrm{~V}$ in PBS and with two concentrations of $\mathrm{H}_{2} \mathrm{O}_{2}$ at different $\mathrm{pH}$ values (see Fig. 1). It can be seen that the lowering of the background current by electrode pretreatment enables a more satisfactory determination of hydrogen peroxide. After analysis of the responses, a potential of $+0.9 \mathrm{~V}$ was chosen for hydrogen peroxide amperometric detection. These studies were performed using the two types of electrochemically pretreated carbon film electrodes: pretreated at fixed potential and acid-cycled electrodes.

Amperometric measurements of $\mathrm{H}_{2} \mathrm{O}_{2}$ were carried out injecting $50 \mu \mathrm{l}$ of $40 \mathrm{mM}$ hydrogen peroxide solution into PBS at $\mathrm{pH} 5-7$ at $+0.9 \mathrm{~V}$. The injection steps show a well-defined shape and the time needed to reach $90 \%$ of the steady-state response was $5 \mathrm{~s}$. The influence of fixed potential pretreatment on the response is shown in Fig. 3. Calibration plots of the acid and fixed potential pretreated electrodes have a higher slope at $\mathrm{pH} 7$ compared with other lower values of $\mathrm{pH}$ (data not shown). After both types of pretreatment, $\mathrm{H}_{2} \mathrm{O}_{2}$ calibration showed a good linearity in a range between $0 \mathrm{mM}$ and $11 \mathrm{mM}$, with a detection limit (three times the signal to noise ratio) of $0.27 \mathrm{mM}$ for polarised and $0.15 \mathrm{mM}$ for acid-cycled 


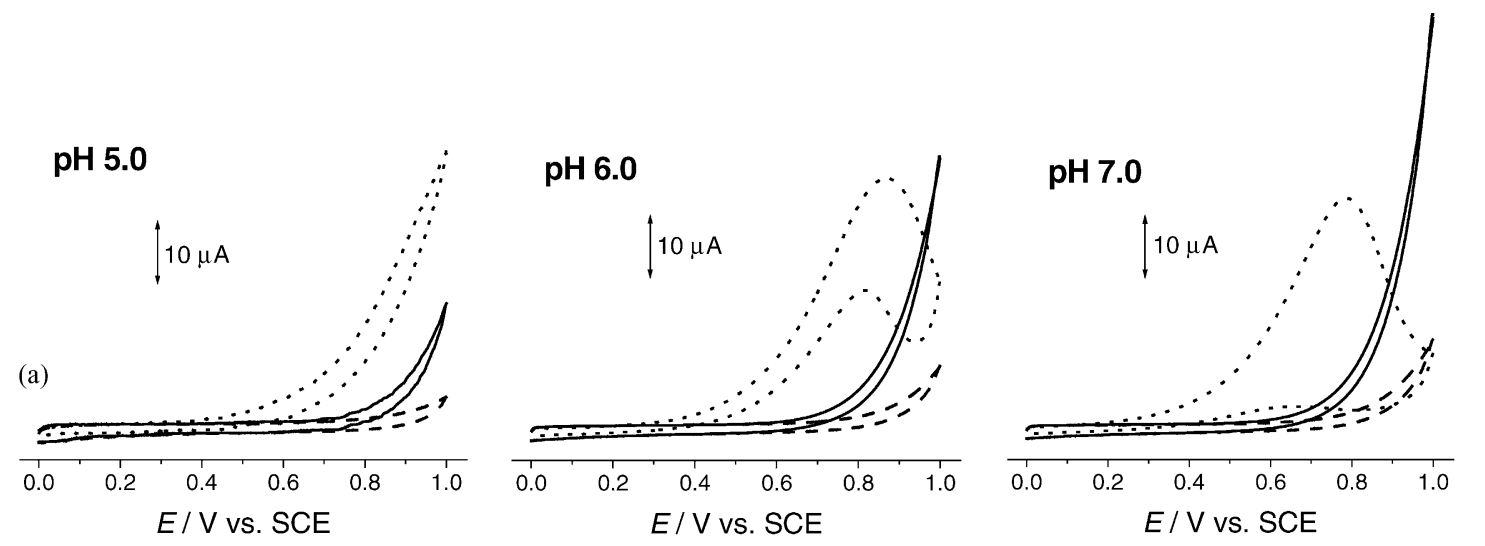

pH 5.0

pH 6.0

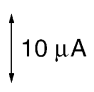

(b)

pH 5.0

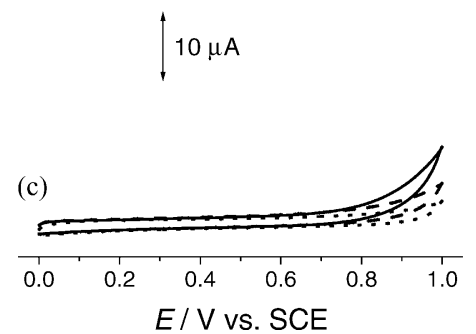

$\mathrm{pH} 6.0$

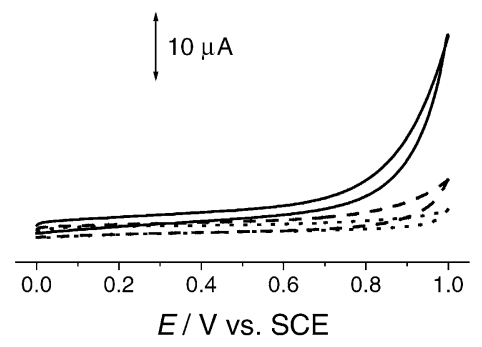

pH 7.0

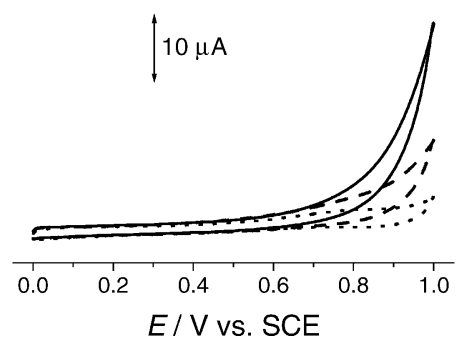

Fig. 1. Cyclic voltammograms at pH 5.0, 6.0 and 7.0 in solutions of (.....) PBS, and with (- . -) $1 \mathrm{mM} \mathrm{H}_{2} \mathrm{O}_{2}$ (一) $10 \mathrm{mM} \mathrm{H}_{2} \mathrm{O}_{2}$ for (a) untreated, (b) pretreated by potential cycling in $1.0 \mathrm{M} \mathrm{HClO}_{4}$ and (c) $+0.9 \mathrm{~V}$ fixed potential pretreated electrodes. Scan rate $50 \mathrm{mV} \mathrm{s}^{-1}$.

electrodes, respectively. The corresponding regression equations of the linear plot were: for the fixed potential pretreated electrode $I / \mu \mathrm{A}=0.0438+2.73 c, R=0.9996$, with a sensitivity of $2.73 \pm 0.09 \mu \mathrm{A} / \mathrm{mM}$ and, for acid-cycled electrodes, $I / \mu \mathrm{A}=0.0168+2.20 c, R=0.9999$, respectively, a sensitivity of $2.20 \pm 0.004 \mu \mathrm{A} / \mathrm{mM}$, where $c$ is the hydrogen peroxide concentration in $\mathrm{mM}$.

At lower potentials, from $0.7 \mathrm{~V}$ upwards, similar linear ranges were found, but the sensitivity was less, as predicted, since a smaller fraction of $\mathrm{H}_{2} \mathrm{O}_{2}$ is being oxidised.

\subsection{Enzyme substrate measurements}

The cylindrical shape of the carbon film sensors means that a good and reproducible contact between the enzymatic layer and the electrode surface is needed as well as a good adhesion of this layer over the whole electrode.

Different immobilisation methods of GOx were investigated in order to obtain a stable and active enzymatic layer. Nafion and glutaraldehyde (GA) were used for this purpose with a view to combining the cross-linking properties of GA with the ability of Nafion to fix the enzymatic membrane on the carbon film surface. In the first experiments, a similar approach to that in [25] was used. The Nafion solution was mixed together with the enzymatic solution mixture described in Section 2. The results and stability of these type of biosensors were compared with results obtained without Nafion in the enzymatic mixture. The optimised composition and procedure are described in the Experimental Section. Results were very similar with and without mixing Nafion. The 


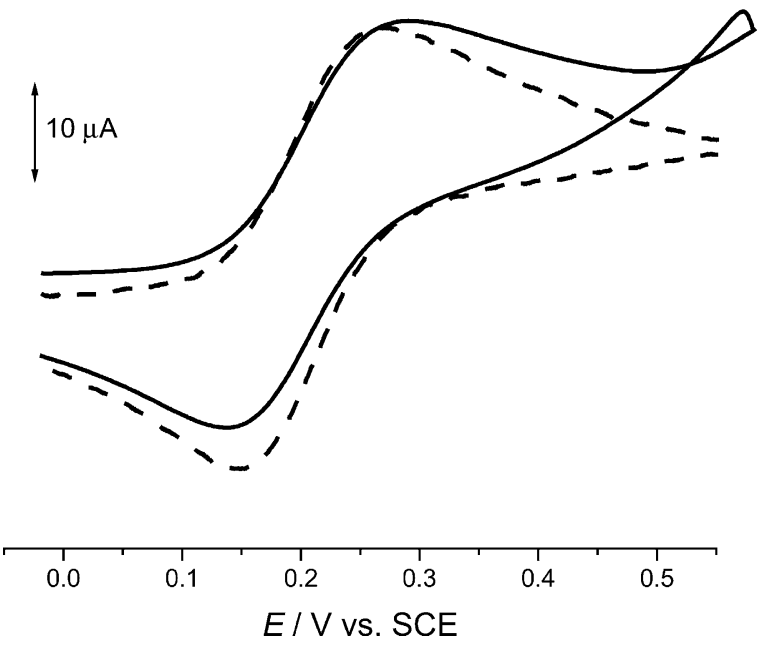

Fig. 2. Cyclic voltammograms after background subtraction for oxidation of $2 \mathrm{mM} \mathrm{K}_{4} \mathrm{Fe}(\mathrm{CN})_{6}$ in $0.4 \mathrm{M} \mathrm{K}_{2} \mathrm{SO}_{4}$ electrolyte at (-) untreated and (-- - - ) acid electrochemically pretreated electrodes. Scan rate $50 \mathrm{mV} \mathrm{s}^{-1}$.

sensitivities were: $0.12 \pm 0.02 \mu \mathrm{A} / \mathrm{mM}(n=3)$ without Nafion and $0.14 \pm 0.02 \mu \mathrm{A} / \mathrm{mM}(n=3)$ with Nafion in the enzyme mixture. However, its inclusion i.e. using Nafion to fix the enzyme on the carbon film electrode, gave a more physically robust sensor, which led to the use of Nafion in the following experiments.

Measurements were performed at fixed applied potential, after stabilisation of the baseline, by injection of $50 \mu$ of $40 \mathrm{mM}$ glucose in PBS into $10 \mathrm{ml}$ of PBS solution containing the enzyme sensor with continuous stirring, detecting the hydrogen peroxide produced. The experimental conditions were those optimised in hydrogen peroxide detection with the unmodified electrode. Kinetic studies of the immobilised enzyme were also carried out. The electrochemical response to increasing concentrations of enzyme substrate was plot-

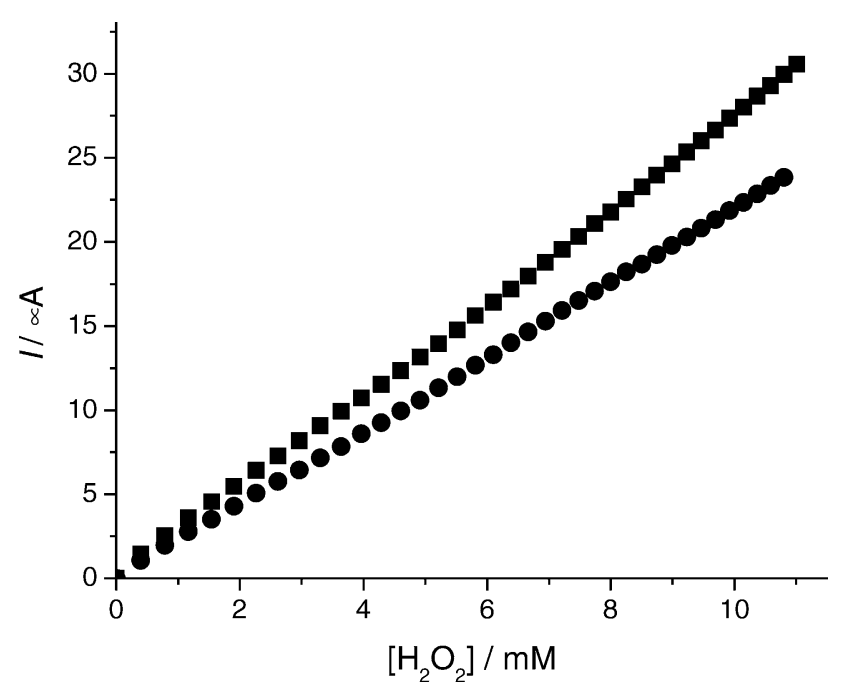

Fig. 3. $\mathrm{H}_{2} \mathrm{O}_{2}$ calibration curves for $(\boldsymbol{\square})$ electrode pretreated at applied potential of $+0.9 \mathrm{~V}$ and $(-)$ acid pretreated electrode for successive additions of $0.2 \mathrm{mM} \mathrm{H}_{2} \mathrm{O}_{2}$ in PBS pH 7.0.

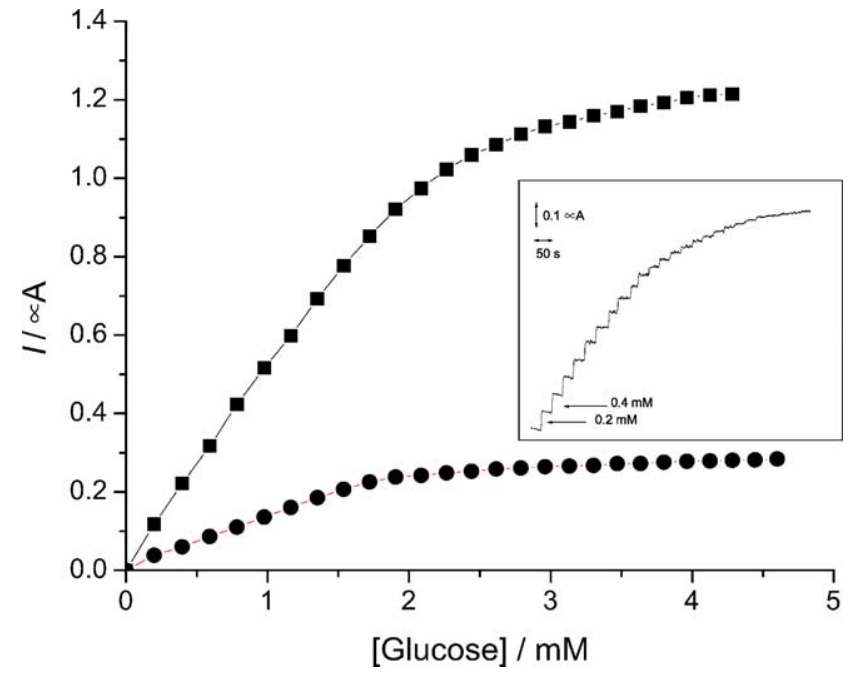

Fig. 4. . Glucose calibration curves for $(\mathbf{\square})+0.9 \mathrm{~V}$ fixed potential pretreated and $(-)$ acid pretreated GOx-based electrode at applied potential of $+0.9 \mathrm{~V}$ for successive additions of $0.2 \mathrm{mM}$ glucose in PBS, $\mathrm{pH}$ 7.0. In the insert the response curve for glucose addition is shown.

ted. Fig. 4 shows the curves for the two types of pretreated electrode in PBS ( $\mathrm{pH} 7)$ at a measurement potential of $+0.9 \mathrm{~V}$ for successive additions of $0.2 \mathrm{mM}$ glucose. The inset shows an example of the experimental traces obtained from which the curve was constructed.

In this situation, carbon film glucose biosensors based on acid-pretreated electrodes showed a linearity range up to $1.17 \mathrm{mM}$ and until $1.54 \mathrm{mM}$ for the fixed potential conditioned electrode. Corresponding detection limits were 59 and $63 \mu \mathrm{M}$, respectively. The regression equations of the linear plots were: $I / \mu \mathrm{A}=0.002+0.165 c$, with $R=0.9991$, a sensitivity of $0.165 \pm 0.003 \mu \mathrm{A} / \mathrm{mM}(n=7)$ for acid pretreated electrode and $I / \mu \mathrm{A}=0.002+0.467 c, R=0.9993$, a sensitivity of $0.467 \pm 0.007 \mu \mathrm{A} / \mathrm{mM}(n=9)$ for fixed potential pretreated electrodes, where $c$ is the glucose concentration in $\mathrm{mM}$. Repetitive measurements over several days showed no loss in response and detection limits were unaffected.

From the Lineweaver-Burk plots, an apparent MichaelisMenten constant of $3.1 \mathrm{mM}$ for acid pretreated and $4.4 \mathrm{mM}$ for fixed potential pretreated electrodes, respectively, was obtained. These values are smaller than those obtained in [18] of $28 \mathrm{mM}$ at a disposable platinum-based electrochemical GOxbased biosensor for glucose representing, in practice, a sensitivity enhancement and lower detection limit (see Fig. 5).

Whereas the two types of pretreated bare carbon electrode showed comparable sensitivities towards hydrogen peroxide, within the enzyme layer significant differences are found. The explanation for this is probably the change in the carbon surface functionalities referred to above in Section 3.1-in particular, at $+0.9 \mathrm{~V}$ there will be surface oxidation, which is evident from the peak beginning at $+0.8 \mathrm{~V}$ from amplification of the cyclic voltammograms at the bare electrode on the positive-directed sweep. To complement these experimental observations, the adhesion of the enzyme layer was seen to be 


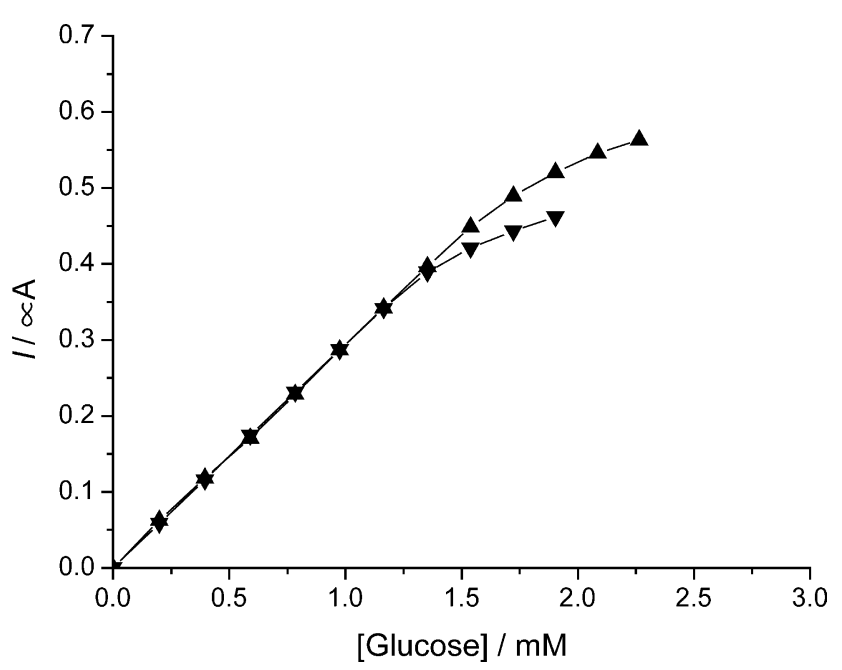

Fig. 5. Glucose calibration curves for pretreated GOx-based electrode at applied potential $+0.9 \mathrm{~V}$ versus SCE for successive additions of $0.2 \mathrm{mM}$ glucose in PBS. Enzyme sensors coated with (ム) $1 \%$ Nafion solution and (v) $5 \%$ Nafion solution.

better after fixed potential pretreatment which suggests some better chemical bonding and thence more efficient oxidation of hydrogen peroxide at the carbon surface. For these reasons the next experiments and comparisons were carried out with electrodes obtained by fixed potential pretreatment.

An alternative strategy for producing a more robust enzyme sensor, than without the inclusion of Nafion and to improve discrimination against possible interferents was investigated. Instead of mixing the Nafion with the other components of the enzyme layer, it was applied over the surface of the prepared sensor half an hour after the enzyme mixture, the sensor having been left in air to dry. In these experimental conditions, two concentrations of Nafion solution were employed, $1 \%$ and $5 \%$ in alcohol. Typical results from glucose injections with sensors prepared in this way are shown in Fig. 4. Michaelis-Menten constants were $10.6 \mathrm{mM}$ for $1 \%$ Nafion and $9.4 \mathrm{mM}$ for $5 \%$ Nafion. As can be seen in Fig. 4, the linear ranges of $0-1.72 \mathrm{mM}$ for a coating from $1 \%$ Nafion solution and of $0-1.35 \mathrm{mM}$ from 5\% Nafion solution are not significantly different from those obtained with mixed Nafion. The corresponding equations are: $I / \mu \mathrm{A}=0.004$ $+0.290 c, R=0.9997$, a sensitivity of $0.29 \pm 0.003 \mu \mathrm{A} / \mathrm{mM}$, detection limit $46 \mu \mathrm{M}$ for $1 \%$ Nafion and $I / \mu \mathrm{A}=0.002+$ $0.290 c, R=0.9998$, a sensitivity of $0.29 \pm 0.002 \mu \mathrm{A} / \mathrm{mM}$, detection limit $27 \mu \mathrm{M}$, respectively for $5 \%$ Nafion, with $c$ the glucose concentration in $\mathrm{mM}$. The electrochemical biosensor coated from $1 \%$ solution showed slightly superior properties and this experimental set-up was employed to test the reproducibility using three different biosensors, and a RSD of $4.1 \%$ was obtained. Repeat measurements on the same day showed a decrease in the limit of detection of the biosensor of $12 \%$, and of $22 \%$ when done four days after biosensor preparation. Results of testing newly prepared biosensors after different time intervals showed that the sensitivity val-

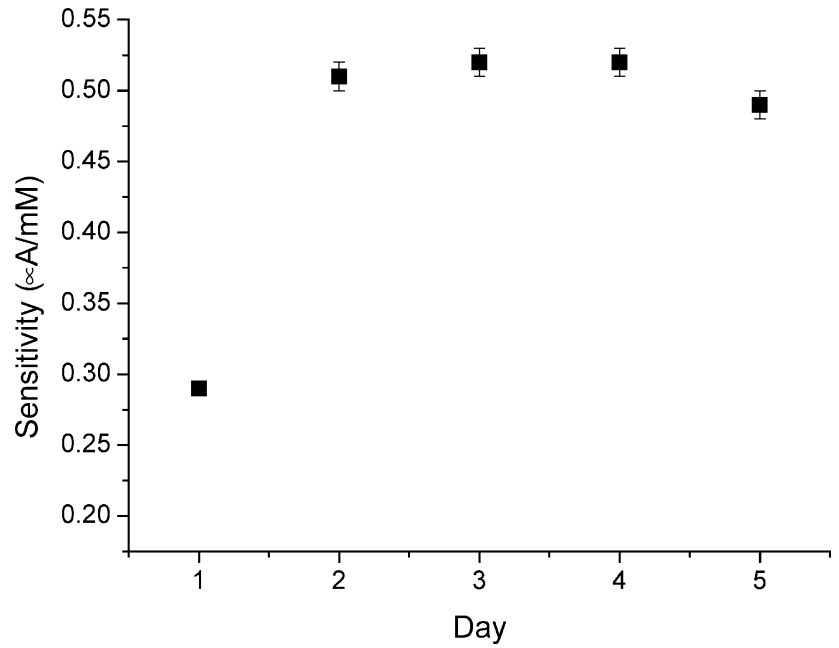

Fig. 6. Sensitivity variation in time of $1 \%$ Nafion coated biosensor. See Fig. 5 for other experimental conditions.

ues increased during the first $24 \mathrm{~h}$, then remained constant but began to decrease slightly on Day 5 (Fig. 6), whilst the Michaelis-Menten constants were unaffected.

In order to seek to minimise interferences, experiments were carried out with biosensors using enzyme layers on carbon film resistors pretreated at fixed potential and coated with $1 \%$ Nafion solution at lower working potentials. The results demonstrated that at these lower values of working potential the sensitivities for glucose detection are small: at $0.8 \mathrm{~V}$ the sensitivity was $0.070 \pm 0.0001 \mu \mathrm{A} / \mathrm{mM}$ and at $0.7 \mathrm{~V}$ was $0.020 \pm 0.0002 \mu \mathrm{A} / \mathrm{mM}$. In conclusion carbon film resistors can be used in these experimental conditions for glucose detection for a very high working potential, i.e., deposition of enzyme layers on carbon film resistors pretreated at fixed potential and coated with $1 \%$ Nafion solution.

The biosensor described above was used for the analysis of enzyme substrates (glucose) in complex matrices, such as wine, as described here.

\subsection{Preliminary analysis of glucose in wines}

Several wines were analysed using the two types of enzyme resistor, with mixed Nafion and coated with Nafion from $1 \%$ solution, using the standard addition method. As expected, for dry wines the response was higher than that obtained by independent analysis, owing to response from other electroactive compounds. Analysis of sweet wines, exemplified by port wine, led to acceptable values in agreement with independent values from the Boehring standard spectrophotometric method (67 \pm 4 and $62 \pm 2 \mathrm{gl}^{-1}$, respectively).

These results demonstrate the potentiality of this type of cheap and disposable sensor both during the fermentation process where the glucose levels are high and in sweet wines. Other approaches based on the deposition of a layer of redox mediator on the carbon film base are currently under investigation. 


\section{Conclusions}

This work has been concerned with the development of electrochemical enzyme biosensors based on low-cost carbon film substrates for use as short-term or disposable biosensors. Evaluation of the system was carried out using determination of glucose with glucose oxidase immobilised by adsorption and the benefits of carbon film pretreatment shown. Application to analysis of sweet wine was demonstrated. They are shown to be a viable alternative to screen printed carbon electrodes.

Future work currently under way concerns the inclusion of redox mediators either as films or mixed in the enzyme layer and the incorporation of other enzymes for the measurement of a variety of enzyme substrates.

\section{Acknowledgements}

Financial support from Fundação para a Ciência e Tecnologia (FCT), ICEMS (Research Unit 103), European Projects QLK3-2000-01311 and HPRN-CT-2002-00186 and the European Union Socrates programme are gratefully acknowledged. Prof. H.D. Liess is thanked for the gift of the electrical resistors.

\section{References}

[1] Biosensors: Fundamentals and Applications, in: A.P.F. Turner, I. Karube, G.S. Wilson (Eds.), Oxford University Press, Oxford, 1987.

[2] G.G. Guilbault, H. Luong, Chimia 42 (1988) 267.
[3] A.B. Gavrilov, A.F. Zueva, O.N. Efimov, V.A. Bogdanovskaya, M.R Tarasevitch, Synth. Met. 60 (1993) 159.

[4] N. Dimcheva, E. Horozova, Z. Jordanova, Z. Naturforsch. 57C (2002) 705 .

[5] M.H. Gil, J.P. Sardinha, M.T. Vieira, M. Vivan, D. Costa, C. Rodrigues, F.-M. Matysik, A.M. Oliveira Brett, Biotechnol. Tech. 13 (1999) 595.

[6] N. Matsumoto, X. Chen, G.S. Wilson, Anal. Chem. 74 (2002) 362.

[7] R.L. McCreery, in: A.J. Bard (Ed.), Electroanalytical Chemistry, vol. 17, Marcel Dekker, New York, 1991, p. 1.

[8] A. Morrin, A.J. Killard, M.R. Smyth, Anal. Lett. 36 (20032021).

[9] K. Lundstrom, Anal. Chim. Acta 146 (1983) 97.

[10] A. Rojo, A. Rosenstratten, D. Anjo, Anal. Chem. 58 (19862988).

[11] S. Ranganathan, R.L. McCreery, Anal. Chem. 73 (2001) 893.

[12] C.M.A. Brett, L. Angnes, H.-D. Liess, Electroanalysis 13 (2001) 765.

[13] O.M.S. Filipe, C.M.A. Brett, Talanta 61 (2003) 643.

[14] S. Sotiropoulou, V. Gavalas, V. Vamvakaki, N.A. Chaniotakis, Biosens. Bioelectron. 18 (2003) 211.

[15] X. Chen, N. Matsumoto, Y. Hu, G.S. Wilson, Anal. Chem. 74 (2002) 368.

[16] M. Alvarez-Icaza, R.D. Schmid, Bioelectrochem. Bioenerg. 33 (1994) 191.

[17] H.M. Wu, R. Olier, N. Jaffrezic-Renault, P. Nyamsi, C. Martelet, Electrochim. Acta 39 (1994) 327.

[18] M. Quinto, I. Losito, F. Palmisano, C.G. Zambonin, Anal. Chim. Acta 420 (2000) 9.

[19] A. Memoli, M.C. Annesini, M. Mascini, S. Papale, S. Petralito, J. Pharm. Biomed. Anal. 29 (2002) 1045.

[20] C. Kurzawa, A. Hengstenberg, W. Schuhmann, Anal. Chem. 74 (2002) 355 .

[21] A.A. Karyakin, O.V. Gitelmacher, E.E. Karyakina, Anal. Chem. 67 (1995) 2419.

[22] A. Amine, J.-M. Kauffmann, G.J. Patriarche, Talanta 40 (1993) 1157.

[23] F. Ricci, A. Amine, G. Palleschi, D. Moscone, Biosens. Bioelectron. 18 (2003) 165.

[24] F.H. Schmidt, Klin. Wochenschrift 39 (1961) 1244.

[25] S.A. Joffari, J.C. Pickup, Biosens. Bioelectron. 11 (1996) 1167. 